\title{
Influence of color word availability on the Stroop color-naming effect
}

\author{
Hyosun Kim and Yang Seok Cho \\ Korea University, Seoul, South Korea \\ AND \\ Motonori Yamaguchi And Robert W. Proctor \\ Purdue University, Purdue, Indiana
}

\begin{abstract}
Three experiments tested whether the Stroop color-naming effect is a consequence of word recognition's being automatic or of the color word's capturing visual attention. In Experiment 1, a color bar was presented at fixation as the color carrier, with color and neutral words presented in locations above or below the color bar; Experiment 2 was similar, except that the color carrier could occur in one of the peripheral locations and the color word at fixation. The Stroop effect increased as display duration increased, and the Stroop dilution effect (a reduced Stroop effect when a neutral word is also present) was an approximately constant proportion of the Stroop effect at all display durations, regardless of whether the color bar or color word was at fixation. In Experiment 3, the interval between the onsets of the to-be-named color and the color word was manipulated. The Stroop effect decreased with increasing delay of the color word onset, but the absolute amount of Stroop dilution produced by the neutral word increased. This study's results imply that an attention shift from the color carrier to the color word is an important factor modulating the size of the Stroop effect.
\end{abstract}

Although people's sensory systems receive large amounts of information about their surroundings, only a fraction of that information is processed at a deeper level. Selective attention is needed in order to process the information that is relevant to the person's intentions and goals. However, in many situations, selective attention seems to be unnecessary for processing certain information. There are cases in which information that is irrelevant to a task is still processed to a level at which it distracts and affects a person's performance. Cognitive psychologists have been interested in this phenomenon for many years, trying to answer the question of why people cannot ignore some information that is irrelevant to their task goals. How irrelevant information affects performance has been studied using the Eriksen flanker task (Eriksen \& Eriksen, 1974), the Simon task (Simon, 1990), and the Stroop color-naming task (Stroop, 1935), among others. In these tasks, an irrelevant stimulus dimension is to be ignored, and a relevant dimension is to be attended and responded to quickly. For example, in the Stroop color-naming task, participants are asked to name the color of the target as quickly as possible while ignoring the meaning of a color word. Despite the fact that the instructions are to ignore the word's meaning, color-naming responses are slower when the meaning and the target color are incongruent than when they are congruent or when no color word is present (Stroop, 1935).

The influence of irrelevant stimuli has long been taken to be evidence of automatic processing (see MacLeod, 1991;
Moors \& De Houwer, 2006). Automatic processing is often described as meeting three criteria (Posner \& Snyder, 1975; Schneider \& Shiffrin, 1977; Shiffrin \& Schneider, 1977): The processing (1) always occurs whenever an appropriate stimulus is present, regardless of whether there is an intention to process the stimulus; (2) is unavailable to consciousness, and so is impossible to stop once it starts; (3) demands zero attentional resources. Many researchers (e.g., Brown, Gore, \& Carr, 2002; MacLeod \& Dunbar, 1988) have suggested that word recognition in the Stroop task is automatic, even though this purported automatic processing does not necessarily meet these criteria in an all-or-none manner. For example, MacLeod and Dunbar proposed that a dimension that is processed more automatically will interfere with one that is processed less automatically, but not vice versa. Because word reading is more automatic than color naming, color naming is influenced by word reading, but word reading is not influenced by color naming. Cohen, Dunbar, and McClelland (1990) developed a parallel distributed processing model of the Stroop effect on the basis of this premise; in this model, the Stroop asymmetry occurs because the associations of color names to color words are stronger than the names' associations to the actual colors. Roelofs (2003) argued against such relative-strength models, advocating instead a production rule model in which goal-referenced control plays an important role. However, his model also treats color words as automatically activating their names, whereas colors do not.

Y.S. Cho, yscho_psych@korea.ac.kr 


\section{Stroop Dilution Effect}

However, Kahneman and Chajczyk (1983) provided evidence suggesting that word recognition in the Stroop task is not automatic. In their Experiment 1, the Stroop effect was reduced by adding a neutral word to the stimulus display of the Stroop task. Specifically, they presented a color bar in the center of the display as the color carrier that, in the single-word condition, was accompanied by a congruent or incongruent color word located immediately above or below the color bar. In the dual-word condition, an additional word, which was neutral with respect to color, was presented in the remaining position, along with the color bar and color word. The Stroop effect was $121 \mathrm{msec}$ in the single-word condition, but only $65 \mathrm{msec}$ in the dual-word condition. This reduced Stroop effect in the dual-word condition is called the Stroop dilution effect (Yee \& Hunt, 1991); that is, the neutral word dilutes the effect of the color word. Kahneman and Chajczyk claimed that the Stroop dilution effect suggests that word reading is only partially automatic, requiring at least some amount of attention. Their argument was that if word reading were completely automatic, no Stroop dilution effect would occur, because color-word processing should be unaffected by neutral-word processing.

Consequently, Kahneman and Chajczyk (1983) proposed an attentional-capture account of the Stroop dilution effect. This account assumes that visual attention is necessary for recognizing the meaning of words. It also assumes that attention can be "captured" by, or directed to, only one word at a time. When a color word and neutral word are presented simultaneously with the color bar, competition for attention between the words occurs, resulting in recognition of only the word to which attention is directed. If the color word captures attention, it will influence color-naming performance. However, if the neutral word captures attention, color-naming performance will be unaffected by the meaning of the color word. Because the probabilities that the color word and the neutral word will capture attention are approximately equal, the Stroop effect on trials with a neutral word should be about half that obtained with no neutral word, which is what Kahneman and Chajczyk found.

\section{Early Visual Interference Account}

Brown, Roos-Gilbert, and Carr (1995) suggested that the Stroop dilution effect is due instead to a visual degradation of feature representations that occurs at early visual processing stages, and they proposed an account based on early visual interference. Unlike Kahneman and Chajczyk's (1983) attentional-capture account, the early visual interference account assumes that two or more words can be recognized automatically, in parallel. However, even though word recognition is an automatic process, feature-based crosstalk among encoded stimuli can occur at an early visual processing stage. Specifically, in a Stroop dilution task, featural interference occurs between a color word and a neutral word presented simultaneously. Brown et al. (1995) suggested that the Stroop effect is "reduced because any color word's input to lexical memory is lower in quality than if a single color word were the only pattern" (p. 1395).

Brown et al. (1995) provided evidence that the Stroop dilution effect is due to features of the dilutor that degrade the processing of the color word's features. They manipulated the type of dilutor (strings of Xs, equal signs, brackets, dashes, or other typographic characters, as well as neutral words) in their Experiments 2 and 3 and found that the Stroop dilution effect increases with the featural complexity of the diluting stimuli. Specifically, nonword dilutors, such as the square brackets and character strings, had diluting influences on the Stroop effect similar to those produced by neutral words. Thus, Brown et al. (1995) concluded that the lexical status of dilutors is not important in determining the magnitude of the Stroop dilution effect. In their view, word recognition in the Stroop task display occurs automatically, and the Stroop dilution effect originates from "outside of the word recognition system per se" (Brown et al., 2002 , p. 229). When a dilutor is presented simultaneously with a color word, feature processing of the color word is degraded, resulting in the reduced efficiency of lexical encoding operations, which provide the basis for word recognition processing.

\section{Revised Attentional-Capture Account}

In opposition to parallel-processing accounts of the type advocated by Brown et al. (1995), Cho, Lien, and Proctor (2006) proposed a revised attentional-capture account. This account differs from that of Kahneman and Chajczyk (1983) in that, in the revised version, attention is directed initially to the color-carrying stimulus, rather than to the stimulus that is at the fixation point. According to Cho et al.'s account, word recognition requires visual attention, and indeed is subject to a serial process. The color carrier initially captures attention on most trials because, regardless of its location in the display, the color carrier is a singleton to which participants need to deploy attention. As in Kahneman and Chajczyk's model, the Stroop effect is a consequence of an attention shift from the target to the distracting color word. Consistent with this account, Cho et al. found that the Stroop dilution effect did not occur when the color carrier was also the color word (i.e., the standard Stroop task, in which the task is to name the color in which a color word is displayed), although the dilution effect did occur when the word was presented as a separate item. According to Cho et al.'s explanation, no Stroop dilution effect occurs when the color word carries the target color because the color attracts attention to the color word on all trials.

In Cho et al.'s (2006) Experiment 4, the magnitude of the Stroop effect did not change as a function of whether the color bar was presented at the fixation point (with a color word at a peripheral location) or at the periphery (with a color word at the fixation point), indicating that the color carrier does indeed capture attention initially, regardless of whether it is displayed at fixation or more peripherally. After the color carrier captures attention, an attention shift toward a flanking stimulus occurs. When 
only a color word is presented with the color bar, this attention shift will be to the color word. However, when a neutral word is also presented, the shift will occur toward either the color word or the neutral word, and the color word will influence color-naming performance only on those trials in which attention shifts from the color carrier to the color word. That is, the Stroop dilution effect is here due to attentional competition between distractor words.

Similarly, Cho et al. (2006) found that the Stroop effect became larger as the exposure duration for the entire display increased. In their Experiment 5A, a color bar or neutral word was presented at the fixation point as the color carrier, with a distracting color word presented at the periphery. The display duration was $100,150,200$, or $250 \mathrm{msec}$, with a pattern mask appearing at the offset of the display. As display duration increased, so did the Stroop effect-from 30 to 39,45 , and $63 \mathrm{msec}$, respectively, for each duration - suggesting that longer durations allow more opportunity for shifts of attention to the color word. In Cho et al.'s Experiment 5B, the color word was presented at fixation as the color carrier, and in this case the magnitude of the Stroop effect did not vary with display duration, taking on values of $140,140,135$, and $138 \mathrm{msec}$ from the short to the long duration. This result showed that the color word was always processed, even at the shortest display duration, when it was the color carrier. The large Stroop effect at short display durations in Experiment 5B suggests that the reduced Stroop effect at those durations in Experiment $5 \mathrm{~A}$ was not primarily due to a failure to read the color word when it was presented only briefly.

\section{The Present Study}

According to Kahneman and Chajczyk (1983), the Stroop effect occurs only when the color word captures attention, and Cho et al. (2006) provided evidence that the size of the Stroop effect is closely related to the probability that the color word will capture attention. The Stroop effect was reduced at short display durations in their Experiment 5A, in which the color word was a separate distractor, but not in their Experiment 5B, in which the color word was the color carrier. However, because the color word was presented at a peripheral location as the distractor in Experiment 5A and at the fixation point as the color carrier in Experiment 5B, display duration could have modulated the perceptual processing of the color word differently in the two experiments. Specifically, Brown et al. (1995) proposed, in the context of their early visual interference account, that when stimuli are presented in cued or attended locations, they are perceptually "processed in a 'protected mode' that largely prevents interference at the early visual processing stage from distractor stimuli with the same type of feature content presented nearby" (p. 1409). Thus, one could argue that the difference in results between Cho et al.'s Experiments $5 \mathrm{~A}$ and $5 \mathrm{~B}$ was due to the color word's being processed in an "unprotected mode" (which allowed early visual interference from distractors) when it was in the periphery, but in a "protected mode" when it was at fixation, in contrast to Cho et al.'s own account, which assumed that attention was drawn to the color word less often when that word was not also the color carrier, relative to when it was.

In the present study, we conducted three experiments to determine whether the finding of a display duration effect when the color word was presented peripherally, but not when it was presented centrally, is due to attentional capture, as Cho et al. (2006) argued, or to a difference in processing mode, as Brown et al.'s (1995) account might suggest. In Experiment 1, display duration was varied in a context in which, according to Brown et al.'s (1995) account, the color word should be processed in an unprotected mode, because it was not the color carrier and was not presented at fixation. The color carrier was a color bar displayed at fixation, and the color word was presented above or below the bar. For trials on which a neutral word was also presented, the neutral word appeared in the other location above or below the color bar. The attentionalcapture account predicts that results similar to those of Cho et al.'s Experiment 5A should be obtained with this display, because increases in duration would allow more opportunity to shift attention from the color bar to a word. In contrast, a finding of no effect of display duration would be more in agreement with the early visual interference account, because according to that theory, interference from distractor stimuli should be independent of display duration.

In Experiment 2, the color carrier was a color bar or the neutral word, and its location (fixation or peripheral) was manipulated, along with display duration. When the color carrier was at fixation, the color word was presented at a peripheral position, as in Cho et al.'s (2006) Experiment $5 \mathrm{~A}$, which showed an effect of display duration; when the color carrier was peripheral, the color word was presented at fixation, as in their Experiment $5 \mathrm{~B}$, which showed no such effect. If the difference in results between their two experiments was due to the color word's being processed in an unprotected mode in Experiment $5 \mathrm{~A}$ and a protected mode in Experiment 5B, as Brown et al.'s (1995) early visual interference account suggests, an influence of display duration should be evident when the color carrier is presented at fixation and the color word at the periphery, but not when the color carrier is presented at the periphery and the color word at fixation.

To examine more directly whether an attention shift occurs from the color carrier to the distractor word, the temporal interval between the onsets of the color carrier and the color word was manipulated in Experiment 3. A color bar was initially presented at fixation as the color carrier, for a variable duration of up to $150 \mathrm{msec}$; at its offset, it was replaced by a color word of the same target color. On half of the trials, a neutral word was presented at display onset either above or below the color carrier, as a distractor. If attention is initially oriented to the color carrier and a shift of attention to a distractor word occurs when such a distractor is present, the color word should affect colornaming performance only at short color bar-color word 
intervals, before an attention shift to the neutral word has occurred.

\section{EXPERIMENT 1}

In Experiment 1, the color carrier was always a color bar at the fixation point, and a color word was presented above or below fixation as a distractor. On half of the trials, a neutral word was displayed as a second distractor, and on half it was not. Both the color word and the neutral word (when present) were in peripheral positions. As in Cho et al.'s (2006) Experiment 5A, four display durations were used, ranging from 100 to $250 \mathrm{msec}$, followed immediately by a pattern mask. Within that time range, a shift of attention to a color word (or neutral word, when present) after processing of the color carrier is more likely to occur as display duration increases. Thus, if the magnitude of the Stroop effect is determined by the likelihood of an attention shift to a color word, the Stroop effect should be larger at longer than at shorter display durations. Also, the presence of a neutral word should reduce the effect by similar proportions at all durations, since the relative probability of shifting attention to one word or the other should not change as display duration increases.

\section{Method}

Participants. Sixteen undergraduates in an introductory psychology course at Purdue University participated in partial fulfillment of a course requirement. All had normal or corrected-to-normal visual acuity and color vision, as determined by self-report.

Stimuli and Apparatus. The experiment was controlled by software developed with the Micro Experimental Laboratory (MEL $2.1)$ system. The stimuli were presented against a dark gray background on the 14-in. display screen of a personal computer, viewed at a distance of approximately $60 \mathrm{~cm}$. A microphone was placed at the participant's sagittal midline and was connected with the computer through a MEL response box. The color carrier, presented at the center of the screen, was a blue, green, red, or yellow color bar $(3.9 \times 0.58 \mathrm{~cm})$. A color word distractor-BLUE $(2.4 \times 0.58 \mathrm{~cm})$, GREEN $(3.0 \times 0.58 \mathrm{~cm})$, RED $(1.7 \times 0.58 \mathrm{~cm})$, or YELLOW $(3.5 \times$ $0.58 \mathrm{~cm}$ ) - was presented on all trials in white uppercase letters either $0.58 \mathrm{~cm}$ above or $0.58 \mathrm{~cm}$ below the color carrier and was congruent on half of the trials and incongruent on the other half. For each of the color words, on half of the trials, one of four neutral words-TALK $(2.4 \times 0.58 \mathrm{~cm})$, PLANE $(3.0 \times 0.58 \mathrm{~cm})$, LOW $(1.7 \times$ $0.58 \mathrm{~cm})$, or ОВЈеСт $(3.5 \times 0.58 \mathrm{~cm})$ - was presented in uppercase letters $0.58 \mathrm{~cm}$ below or above the color carrier, on the side opposite the color word; on the other half of the trials, no neutral word appeared. Participants were asked to name the color of the target stimulus by saying "blue," "green," "red," or "yellow" into the microphone interfaced with the computer.

Procedure. Each participant performed in a 24-trial practice block and two 192-trial test blocks. The participants were tested individually in a dark room. Each trial began when a fixation " + " sign $(0.4 \times 0.5 \mathrm{~cm})$ appeared at the center of the screen for $500 \mathrm{msec}$; the participants were asked to stare at this point while it was present. At the offset of the fixation sign, the target display, which consisted of the color carrier and a color word with or without a neutral word, was presented for $100,150,200$, or $250 \mathrm{msec}$, and then a masking display of three rows of six X characters, each centered at the color carrier location, was flashed for $250 \mathrm{msec}$. Participants were instructed to name the color of the color carrier as quickly as possible by saying "blue," "green," "red," or "yellow." An incorrect response was followed by a $250-\mathrm{msec}$ feedback tone. The plus sign for the next trial appeared $1,750 \mathrm{msec}$ after a correct response, or $1,500 \mathrm{msec}$ after the feedback tone when a response was incorrect.

\section{Results}

In this experiment and the following ones, RTs less than $150 \mathrm{msec}$ or greater than $2 \mathrm{sec}$ (here, $1.2 \%$ of all trials) were removed as outliers. Mean RTs and percentage errors (PEs) were calculated for each participant as a function of congruency (congruent or incongruent color word), distractor (neutral word present or absent), and display duration $(100,150,200$, or $250 \mathrm{msec})$. ANOVAs were conducted on the RT and PE data, with those variables as within-subjects factors. Mean RTs and PEs are shown in Table 1.

The results showed a Stroop effect that was an increasing function of display duration. The Stroop effect was larger when a color word was presented alone as a distractor than when both a color word and a neutral word were presented, demonstrating a Stroop dilution effect. This dilution effect tended (nonsignificantly) to be larger at longer display durations. The following subsections provide detailed statistical analyses of these results.

Reaction time. There was a main effect of display duration $\left[F(3,45)=10.25, M S_{\mathrm{e}}=498, p<.0001\right]$ : Mean RTs lengthened as display duration increased $(M \mathrm{~s}=590$, 590,600 , and $609 \mathrm{msec}$ for display durations of 100 , 150,200 , and $250 \mathrm{msec}$, respectively). Distractor was not a significant factor $[F(1,15)<1]$, with mean RTs of $598 \mathrm{msec}$ both when a neutral word was presented and when it was not.

The main effect of congruency, reflecting a 76-msec Stroop effect, was significant $[F(1,15)=191, p<.0001$, $\left.M S_{\mathrm{e}}=1,925\right]$ : Mean RTs were shorter when the color carrier and the meaning of the color word were congruent $(M=560 \mathrm{msec})$ than when they were incongruent $(M=636 \mathrm{msec})$. Notably, the interaction between display duration and congruency was also significant $[F(3,45)=$ 7.36, $\left.M S_{\mathrm{e}}=756, p=.0004\right]$ : The Stroop effect increased as display duration increased, with means of $56,67,83$, and $99 \mathrm{msec}$ for durations of 100, 150, 200, and $250 \mathrm{msec}$, respectively (see Table 1).

Table 1

Mean Reaction Time (RT, in Milliseconds) and Percentage of Error (PE) in Experiment 1 As a Function of Congruency, Neutral Word, and Display Duration

\begin{tabular}{|c|c|c|c|c|c|c|}
\hline \multirow{2}{*}{$\begin{array}{l}\text { Duration and } \\
\text { Neutral Word }\end{array}$} & \multicolumn{2}{|c|}{ Congruent } & \multicolumn{2}{|c|}{$\underline{\text { Incongruent }}$} & \multicolumn{2}{|c|}{$\underline{\text { Stroop Effect }}$} \\
\hline & RT & $\mathrm{PE}$ & RT & $\mathrm{PE}$ & $\mathrm{RT}$ & $\mathrm{PE}$ \\
\hline \multicolumn{7}{|l|}{$100 \mathrm{msec}$} \\
\hline No neutral word & 557 & 0.00 & 631 & 0.56 & 74 & 0.56 \\
\hline Neutral word & 569 & 1.04 & 608 & 0.00 & 39 & -1.04 \\
\hline \multicolumn{7}{|l|}{$150 \mathrm{msec}$} \\
\hline No neutral word & 548 & 0.26 & 631 & 0.80 & 83 & 0.54 \\
\hline Neutral word & 566 & 0.53 & 617 & 0.26 & 51 & -0.27 \\
\hline \multicolumn{7}{|l|}{$200 \mathrm{msec}$} \\
\hline No neutral word & 543 & 1.05 & 649 & 1.86 & 106 & 0.81 \\
\hline Neutral word & 574 & 0.78 & 634 & 0.54 & 60 & -0.24 \\
\hline \multicolumn{7}{|l|}{$250 \mathrm{msec}$} \\
\hline No neutral word & 552 & 0.52 & 672 & 3.73 & 120 & 3.19 \\
\hline Neutral word & 569 & 0.52 & 646 & 2.11 & 77 & 1.59 \\
\hline
\end{tabular}


Congruency also interacted with distractor $[F(1,15)=$ $\left.27.45, M S_{\mathrm{e}}=882, p<.0001\right]$, indicating a Stroop dilution effect. The Stroop effect was $96 \mathrm{msec}$ when only a color word was presented, but was reduced to $56 \mathrm{msec}$ when a neutral word was also presented. As can be seen in Table 1, this reduction was accomplished by the neutral word increasing RTs by $20 \mathrm{msec}$ on congruent trials and decreasing them by the same amount on incongruent trials [respectively, $F_{\mathrm{s}}(1,15)=13.87$ and $18.06, M S_{\mathrm{e}} \mathrm{s}=$ 871 and $672, p s<.001$ ], which would be expected if the neutral word reduced activation from the color word for both trial types. The Stroop dilution effect tended to be smaller at the two shortest durations $(M=32.5 \mathrm{msec})$ than at the two longest durations $(M=43.5 \mathrm{msec})$, much as it was in Cho et al.'s (2006) experiment $(M \mathrm{~s}=33$ and $56.5 \mathrm{msec}$, respectively). However, the three-way interaction of congruency, distractor, and duration was not significant $[F(3,45)<1]$, and simple-effect comparisons showed that the Stroop dilution effect was significant at all durations $(p \mathrm{~s}<.05)$.

Percentage error. The overall PE was $0.91 \%$. Display duration was significant $\left[F(3,45)=8.29, M S_{\mathrm{e}}=2.92\right.$, $p=.0002]$. PEs increased with display duration, with means of $0.40 \%, 0.46 \%, 1.06 \%$, and $1.72 \%$ for durations of $100,150,200$, and $250 \mathrm{msec}$, respectively. Scheffé tests showed PEs to be significantly lower for display durations of 100 and $150 \mathrm{msec}$ than for durations of 200 and $250 \mathrm{msec}$. The main effect of congruency was also significant $\left[F(1,15)=5.64, M S_{\mathrm{e}}=4.69, p=.0314\right]$; the PEs were $0.59 \%$ when the color word was congruent with the color carrier and $1.23 \%$ when the color word was incongruent with the color carrier, showing a Stroop effect of $0.64 \%$.

Congruency interacted with display duration $[F(3,45)=$ $\left.7.30, M S_{\mathrm{e}}=3.10, p=.0004\right]$. As in the RT data, the Stroop effect for PEs increased as display duration increased (effects of $-0.24 \%, 0.14 \%, 0.28 \%$, and $2.39 \%$ for durations of $100,150,200$, and $250 \mathrm{msec}$, respectively). The interaction of congruency with distractor approached significance $\left[F(1,15)=4.34, M S_{\mathrm{e}}=5.93, p=.0548\right]$. Finally, consistent with Stroop dilution, the Stroop effect for PEs was $1.3 \%$ when no neutral word was presented but was reduced to $0.01 \%$ when a neutral word was presented. No other terms were significant.

\section{Discussion}

The results replicated most of the findings of Cho et al.'s (2006) Experiment 5A, even though a color bar was used as the color carrier and the color and neutral words were presented above or below fixation. A 76-msec Stroop effect was obtained. Also, as in Kahneman and Chajczyk's (1983) experiment, in which the color carrier was a color bar and a color word and a neutral word appeared as distractors, the effect of the color word was larger when only it was presented as a distractor $(96 \mathrm{msec})$ than when it appeared with a neutral word $(56 \mathrm{msec})$, showing a Stroop dilution effect.

Display duration modulated the magnitude of the Stroop effect, even though the color word and the neu- tral word were presented at peripheral locations. As display duration increased, the influence of the color word on color-naming performance increased, resulting in a larger Stroop effect, regardless of whether a neutral word was present or not. Note that this increase in Stroop effect size occurred in the absence of an increase in RTs for the baseline congruent trials. This pattern of a larger Stroop effect with increasing duration replicates the finding from Cho et al.'s (2006) Experiment 5A, providing evidence that the influence of a color word on color-naming performance increases as the likelihood of a shift of attention from the color carrier to the color word increases.

The absolute size of the Stroop dilution effect also tended to increase with display duration, as in Cho et al.'s (2006) Experiment 5A, but this pattern was far from statistically significant. This lack of significance is likely due to low statistical power for this higher-order interaction, since the Stroop effect becomes larger with increases in display duration, both when a neutral word is present and when it is not. Although the interaction was significant in Cho et al.'s Experiment 5A, even there, it barely exceeded the .05 level. The prediction of the attention-shifting hypothesis is that the Stroop effect in the presence of a neutral word should be a relatively constant proportion of this effect's size when a neutral word is not present. Consistent with this prediction, the Stroop dilution effect ranged between proportions of .53 and .64 for the four display durations.

\section{EXPERIMENT 2}

When a color word was presented at fixation as the color carrier in Cho et al.'s (2006) Experiment 5B, its influence on performance was not modulated by display duration. Cho et al. interpreted this result as indicating that attention was always directed to the color word because it was the color carrier. However, according to Brown et al.'s (1995) early visual interference account, stimuli presented at cued or attended locations are processed in a protected mode, which prevents perceptual interference from distractors at early visual processing stages. One might thus argue that the lack of a display duration effect when a color word is presented at fixation could be due to this word's being processed in a protected mode.

Experiment 2 was designed to investigate whether the lack of influence of display duration on the Stroop effect in Cho et al.'s (2006) Experiment 5B was due to the central location of the color word or to its role as the color carrier. As in Cho et al.'s Experiment 5A, the color carrier was a color bar or a neutral word, and the color word was presented as a distractor on all trials. This target display was presented for 100 or $250 \mathrm{msec}$. To determine whether the influence of display duration on the Stroop effect is modulated by the location of the color word, we manipulated location: The color carrier was presented either at the fixation point or above or below it. When the color carrier was presented at the fixation point, the color word was presented above or below it, and when the color carrier 
was presented above or below the fixation point, the color word was presented at fixation.

According to Cho et al.'s (2006) attentional-capture account, the magnitude of the Stroop effect is determined by the likelihood of an attention shift to the color word. Thus, the effect of the color word should be larger when the color carrier is a color bar rather than a neutral word, on the assumption that a colored neutral word takes more time to process than does a color bar (see Cho et al., 2006, Experiment 3). Also, the magnitude of the Stroop effect should be larger at the $250-\mathrm{msec}$ than at the $100-\mathrm{msec}$ duration, because a shift of attention to the color word after processing the color carrier is more likely to occur during the longer display duration. Modulation of the congruency effect by display duration should then not differ with the location at which the color word is presented, in contrast to the prediction of the early visual interference account.

\section{Method}

Participants. Sixteen undergraduates enrolled in introductory psychology at Korea University participated in partial fulfillment of a course requirement. All had normal or corrected-to-normal visual acuity and color vision, as determined by self-report.

Stimuli and Apparatus. The experiment was controlled by E-Prime (version 1.1). The stimuli were presented on the 15-in. display screen of a personal computer and were viewed at a distance of approximately $60 \mathrm{~cm}$. The color word 빨 강 (palgang, or "red" in Korean), 노랑 (norang, "yellow"), 초록 (chorok, "green"), or 파 랑 (parang, "blue") was spoken into a microphone interfaced with the computer through an E-Prime response box. The microphone was placed at the participant's sagittal midline. The color carrier was a color bar $\left(1.96 \times 0.8 \mathrm{~cm}, 1.87^{\circ} \times 0.76^{\circ}\right)$ on half of the trials and a neutral word $\left(1.60 \times 0.8 \mathrm{~cm}, 1.53^{\circ} \times 0.76^{\circ}\right)$ on the other half. Four neutral words were selected that had the same number of syllables as the color words and a similar frequency in the language, but no color meaning: 중 심 (“center"), 전 기 ("electricity"), 함 성 ("shout"), and 향 수 ("perfume"). The carrier stimulus was presented at one of three possible locations - the fixation point (central) on half of the trials, or immediately above or below this point (peripheral) on the other half - in red, yellow, green, or blue. A color word distractor $(1.60 \times$ $0.8 \mathrm{~cm}, 1.53^{\circ} \times 0.76^{\circ}$ ) was presented at an adjacent location in white letters on a dark background. That is, when the color carrier was presented at the fixation point, the distractor was presented above or below it, and when the color carrier was presented above or below the fixation point, the distractor was presented at fixation.

Procedure. Each participant performed in a 24-trial practice block and two 192-trial test blocks. The participants were tested individually in a dark room. Each trial began when a fixation "+" $\operatorname{sign}\left(0.4 \times 0.5 \mathrm{~cm}, 0.38^{\circ} \times 0.48^{\circ}\right)$ was presented at the center of the screen for $250 \mathrm{msec}$. Participants were asked to stare at this point while it was present. The target display, which consisted of either a color bar or a colored neutral word with the color word, was presented for either 100 or $250 \mathrm{msec}$. Afterward, a masking display consisting of three rows of three Xs was flashed for $250 \mathrm{msec}$. Participants were asked to name the color of the color carrier by saying palgang ("red"), norang ("yellow"), chorok ("green"), or parang ("blue"). An incorrect response was followed by a 300-msec feedback tone. The plus sign for the next trial appeared $1,700 \mathrm{msec}$ after a correct response, or 1,400 msec after the feedback tone when a response was incorrect.

\section{Results}

In total, $0.5 \%$ of the trials were excluded according to the criteria described for Experiment 1. Mean RTs and PEs were calculated for each participant as a function of congruency (congruent or incongruent color word), color carrier (bar or neutral word), carrier location (central or peripheral), and display duration (100 or $250 \mathrm{msec}$ ). ANOVAs were conducted on the RT and PE data, with all of the listed variables as within-subjects factors. Mean RTs and PEs are shown in Table 2. As in Experiment 1, the Stroop effect was larger at the long than at the short display duration, and a Stroop dilution effect was evident that tended to increase at the long duration. Most notably, these effects did not depend on whether the target was located at fixation or at one of the peripheral locations. Details of these results follow.

Reaction time. The main effect of display duration was significant $\left[F(1,15)=12.77, M S_{\mathrm{e}}=898, p=\right.$ .0028], with shorter RTs when the display duration was $100 \mathrm{msec}(M=555 \mathrm{msec})$ than when it was $250 \mathrm{msec}$ $(M=568 \mathrm{msec})$. The main effect of color carrier was also significant $\left[F(1,15)=11.92, M S_{\mathrm{e}}=2,554, p=.0036\right]$ : Responses were faster when the color carrier was a color $\operatorname{bar}(M=550 \mathrm{msec})$ than when it was a neutral word $(M=$ $573 \mathrm{msec}$ ).

The Stroop effect, shown by the main effect of congruency, was evident $\left[F(1,15)=68.84, M S_{\mathrm{e}}=3,244, p<\right.$ $.0001]$. The mean RT was $59 \mathrm{msec}$ shorter when the color carrier and the meaning of the color word were congruent $(M=532 \mathrm{msec})$ than when they were incongruent $(M=$ $591 \mathrm{msec}$ ). The interaction of congruency and carrier location did not reach significance $[F(1,15)=1.09, p=$ .3139], indicating that the Stroop effects were of similar size when the carrier was presented at the central and at the peripheral location (see Table 2). Congruency did interact with display duration, though $\left[F(1,15)=11.20, M S_{\mathrm{e}}=\right.$ $422, p=.0044]$; as expected, the Stroop effect was larger when the display was presented for $250 \mathrm{msec}(67 \mathrm{msec})$ than when it was presented for $100 \mathrm{msec}(50 \mathrm{msec})$.

Color carrier and congruency also interacted $[F(1,15)=$ $\left.11.29, M S_{\mathrm{e}}=1,211, p=.0043\right]$, indicating a Stroop dilution effect. The Stroop effect was $74 \mathrm{msec}$ when the color

Table 2

Mean Reaction Time (RT, in Milliseconds) and Percentage of

Error (PE) in Experiment 2 As a Function of Congruency, Color Carrier, Display Duration, and Carrier Location (Central or Peripheral)

\begin{tabular}{|c|c|c|c|c|c|c|}
\hline \multirow{2}{*}{$\begin{array}{l}\text { Duration and } \\
\text { Color Carrier }\end{array}$} & \multicolumn{2}{|c|}{ Congruent } & \multicolumn{2}{|c|}{ Incongruent } & \multicolumn{2}{|c|}{ Stroop Effect } \\
\hline & RT & $\overline{\mathrm{PE}}$ & RT & $\overline{\mathrm{PE}}$ & RT & $\mathrm{PE}$ \\
\hline \multicolumn{7}{|c|}{ Central } \\
\hline $100 \mathrm{msec}$ & & & & & & \\
\hline Bar & 517 & 0.52 & 569 & 3.65 & 52 & 3.13 \\
\hline Neutral word & 549 & 1.04 & 588 & 3.13 & 39 & 2.09 \\
\hline \multicolumn{7}{|l|}{$250 \mathrm{msec}$} \\
\hline Bar & 509 & 0.00 & 585 & 4.17 & 76 & 4.17 \\
\hline Neutral word & 550 & 2.08 & 605 & 0.52 & 55 & -1.56 \\
\hline \multicolumn{7}{|c|}{ Peripheral } \\
\hline $100 \mathrm{msec}$ & & & & & & \\
\hline Bar & 511 & 1.56 & 582 & 6.87 & 71 & 5.31 \\
\hline Neutral word & 542 & 4.17 & 582 & 4.17 & 40 & 0.00 \\
\hline \multicolumn{7}{|l|}{$250 \mathrm{msec}$} \\
\hline Bar & 519 & 0.00 & 615 & 3.69 & 96 & 3.69 \\
\hline Neutral word & 560 & 2.08 & 604 & 2.08 & 44 & 0.00 \\
\hline
\end{tabular}


carrier was a color bar, but only $45 \mathrm{msec}$ when the carrier was a neutral word. As in Experiment 1, the mean Stroop dilution effect was smaller at the short duration $(M=22 \mathrm{msec})$ than at the long one $(M=36.5 \mathrm{msec})$, but the effect was significant at both durations $(p<.05)$, and the three-way interaction of congruency, duration, and color carrier did not approach statistical significance $\left[F(1,15)=1.16, M S_{\mathrm{e}}=654, p=.299\right]$. However, the increase in Stroop effect size at the longer display duration was significant when there was no neutral word in the display $[F(1,15)=7.41, p=.016]$, but not when a neutral word was present $[F(1,15)=1.17, p=.296]$. No other term in the overall ANOVA was significant.

Percentage error. The overall PE was $2.48 \%$. The congruency main effect was significant $[F(1,15)=8.06$, $\left.M S_{\mathrm{e}}=35.05, p=.0124\right]$ : The PE was $1.43 \%$ when the color carrier and the meaning of the color word distractor were congruent but $3.53 \%$ when they were incongruent, showing a Stroop effect. The interaction of congruency and color carrier was also significant $[F(1,15)=8.90$, $\left.M S_{\mathrm{e}}=27.95, p=.0093\right]$, showing a Stroop dilution effect; the Stroop effect was $4.07 \%$ when the color carrier was a color bar, but only $0.13 \%$ when the color carrier was a neutral word. No other main effect or interaction was significant.

\section{Discussion}

As in Cho et al.'s (2006) Experiment 5A, a 59-msec Stroop effect was obtained and a Stroop dilution effect was evident: The Stroop effect was $74 \mathrm{msec}$ when the color carrier was a color bar, but only $45 \mathrm{msec}$ when the color carrier was a neutral word. Display duration modulated the Stroop effect, as in Experiment 1; as display duration increased, the magnitude of Stroop interference also increased, resulting in a larger effect. Although the effect of display duration might be attributed to difficulty in reading the color word, the fact that the display duration effect was not modulated significantly by the location of the color word argues against this possibility. Most importantly, regardless of whether the color word was presented at the fixation point or at a peripheral location, display duration influenced the magnitude of the Stroop effect. This outcome is consistent with the view that the longer the color word is visible, the greater the probability that attention will be shifted to it, away from the color carrier.

Also as in Experiment 1, the absolute size of the Stroop dilution effect for RTs tended to be larger at the long display duration than at the short one. Although the three-way interaction of congruency, distractor, and display duration was not significant, the Stroop effect was larger at the longer duration than at the shorter one only when there was no neutral word present. In addition, the proportions of the Stroop effect size with versus without a neutral word present were approximately equal for both display durations, although the proportions tended to be larger (because the base Stroop effect was smaller) when the color carrier was at the central location (.75 and .72 for the short and long durations, respectively) than when the carrier was at a peripheral location (.56 and .46 , respectively).

\section{EXPERIMENT 3}

The Stroop effect was larger when the stimulus display was presented for $250 \mathrm{msec}$ rather than $100 \mathrm{msec}$ in Experiment 2, regardless of whether the color word was displayed at the fixation point or more peripherally. However, the results of Experiments 1 and 2 do not directly show that an attention shift to the color word occurred after the color carrier initially captured attention. Thus, Experiment 3 was conducted to provide direct evidence that an attention shift to the color word influences the magnitude of the Stroop effect. In Experiment 3, a color bar was presented as the color carrier at the center of the display and was replaced after a variable amount of time by a color word in the same visual color. A neutral word was presented above or below the color carrier on half of the trials, and no neutral word was presented on the other half. Even though the shape of the color carrier changed from a bar to a color word, the location and color remained the same. Stimulus onset asynchronies (SOAs) of 0, 50, 100 , and $150 \mathrm{msec}$ were used because previous research has shown that increases beyond $150 \mathrm{msec}$ have little influence on the Stroop color-naming effect (Glaser \& Glaser, 1982).

The size of the Stroop effect should increase as SOA decreases because the color word is available earlier in the processing of the target color. Most importantly, if a shift of attention to a distractor occurs after attention is initially focused on the color carrier, a larger Stroop dilution effect should be obtained at longer SOAs. That is, when the color bar appears, attention will initially be oriented toward it to process the color. After this initial orientation, an attention shift is likely to occur to the neutral word, if one is present. For trials with longer SOAs, an attention shift to the neutral word is more likely to occur before the bar is replaced by the colored color word, resulting in the meaning of the color word having no influence on performance. However, for trials with shorter SOAs, an attention shift to the neutral word is not likely to occur before the color bar is replaced by the colored color word. Because attention is already fixed on the color carrier, the color word should be directly processed after its onset, resulting in a correspondence effect of the meaning of the color word on color-naming performance.

\section{Method}

Participants. Sixteen undergraduates enrolled in introductory psychology at Korea University participated in partial fulfillment of a course requirement. All had normal or corrected-to-normal visual acuity and color vision, as determined by self-report.

Stimuli and Apparatus. The apparatus was identical to that used in Experiment 2. The color carrier, which was presented at the center of the screen, was a red, yellow, green, or blue color bar that was replaced by one of four color words-빨 강 ("red"), 노 랑 (“yellow"), 초록 ("green"), or 파링 ("blue")—after a certain amount of time, but the color of the stimuli remained the same. On half of the trials, the color bar and the later-presented color word distractor were congruent, and on the other half, they were incongruent. One of four neutral words-중 심 ("center"), 전 기 ("electricity"), 함 성 ("shout"), or 향 수 ("perfume")—was presented either above or below the color carrier on half of the trials, and on the other half, no 


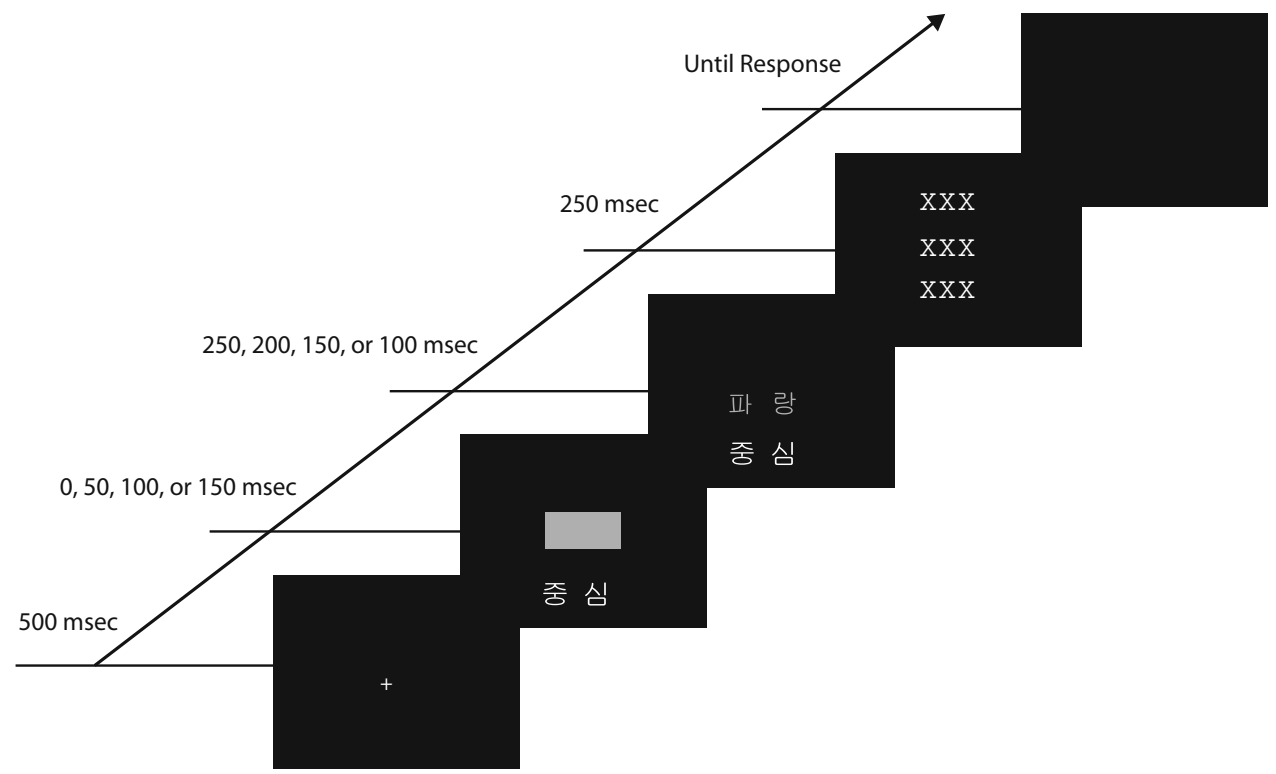

Figure 1. Example trial sequence for Experiment 3. The target color in all of the example displays was red, depicted in the figure by gray.

neutral word was present. The neutral word was presented simultaneously with the color carrier and remained throughout the trial.

Procedure. Each participant performed a 24-trial practice block and two 192-trial test blocks. The target stimuli consisted of a color bar and color word and were presented sequentially for a total of $250 \mathrm{msec}$. The red, yellow, green, or blue color bar was presented in the center of the screen for $0,50,100$, or $150 \mathrm{msec}$ and was then replaced by a colored color word, which was presented for a further $250,200,150$, or $100 \mathrm{msec}$, respectively, depending on the initial presentation time of the color bar. The color word was always presented in the same color as the color bar. On half of the trials, a neutral word was presented either above or below the color carrier for $250 \mathrm{msec}$, and on the remaining half, no neutral word was presented. Participants were asked to name the color of the target stimulus by saying "red," "yellow," "green," or "blue" in Korean (as described in Experiment 2) into a microphone interfaced with the computer. The stimulus presentation order is depicted in Figure 1.

\section{Results}

In total, $0.59 \%$ of the trials were removed, using the same RT cutoff criteria as in the previous experiments. Mean RTs and PEs were calculated for each participant as a function of congruency (congruent or incongruent color word), neutral word (present or absent), and SOA $(0,50,100$, or $150 \mathrm{msec})$. ANOVAs were conducted on the RT and PE data, with the listed variables as withinsubjects factors. Mean RTs and PEs are shown in Table 3. As expected, the Stroop effect was a decreasing function of SOA; despite this decrease, the Stroop dilution effect tended to be larger at the long SOAs.

Reaction time. RTs were significantly influenced by SOA $\left[F(3,45)=13.27, M S_{\mathrm{e}}=1,289, p<.0001\right]$. Scheffé tests showed that the mean RT was longer at the 0 -msec SOA $(609 \mathrm{msec})$ than at the 50-, 100-, and 150-msec SOAs $(583,582$, and $570 \mathrm{msec}$, respectively). The congru- ency main effect was significant $\left[F(1,15)=59.57, M S_{\mathrm{e}}=\right.$ $7,580, p<.0001]$ : RTs were $84 \mathrm{msec}$ shorter on average when the color word was congruent with the target color (544 $\mathrm{msec})$ than when it was incongruent $(628 \mathrm{msec})$. Also, congruency interacted with $\operatorname{SOA}[F(3,45)=11.30$, $M S_{\mathrm{e}}=1,496, p<.0001$; see Figure 2]. The longer the color bar was presented, the smaller the Stroop effect (effects of $123,94,75$, and $45 \mathrm{msec}$ at the $0-, 50-, 100-$, and 150-msec SOAs, respectively).

A Stroop dilution effect was also obtained, as indicated by the congruency $\times$ neutral word interaction $[F(1,15)=$ $\left.6.72, M S_{\mathrm{e}}=1,008, p=.0204\right]$. When no neutral word was present, the Stroop effect was $94 \mathrm{msec}$; this was reduced to $74 \mathrm{msec}$ when a neutral word was presented

Table 3

Mean Reaction Time (RT, in Milliseconds) and Percentage of Error (PE) in Experiment 3 As a Function of Congruency, Neutral Word, and Stimulus Onset Asynchrony (SOA)

\begin{tabular}{|c|c|c|c|c|c|c|}
\hline \multirow{2}{*}{$\begin{array}{c}\text { SOA and } \\
\text { Neutral Word }\end{array}$} & \multicolumn{2}{|c|}{ Congruent } & \multicolumn{2}{|c|}{ Incongruent } & \multicolumn{2}{|c|}{ Stroop Effect } \\
\hline & RT & $\mathrm{PE}$ & RT & $\mathrm{PE}$ & RT & $\mathrm{PE}$ \\
\hline \multicolumn{7}{|l|}{$0 \mathrm{msec}$} \\
\hline No neutral word & 549 & 0.00 & 679 & 4.69 & 130 & 4.69 \\
\hline Neutral word & 545 & 0.00 & 660 & 6.49 & 115 & 6.49 \\
\hline \multicolumn{7}{|l|}{$50 \mathrm{msec}$} \\
\hline No neutral word & 534 & 0.52 & 627 & 2.60 & 93 & 2.08 \\
\hline Neutral word & 537 & 0.00 & 633 & 4.21 & 96 & 4.21 \\
\hline \multicolumn{7}{|l|}{$100 \mathrm{msec}$} \\
\hline No neutral word & 537 & 0.00 & 630 & 3.65 & 93 & 3.65 \\
\hline Neutral word & 553 & 0.52 & 609 & 1.56 & 56 & 1.04 \\
\hline \multicolumn{7}{|l|}{$150 \mathrm{msec}$} \\
\hline No neutral word & 542 & 0.52 & 604 & 0.52 & 62 & 0.00 \\
\hline Neutral word & 552 & 0.00 & 580 & 1.04 & 28 & 1.04 \\
\hline
\end{tabular}




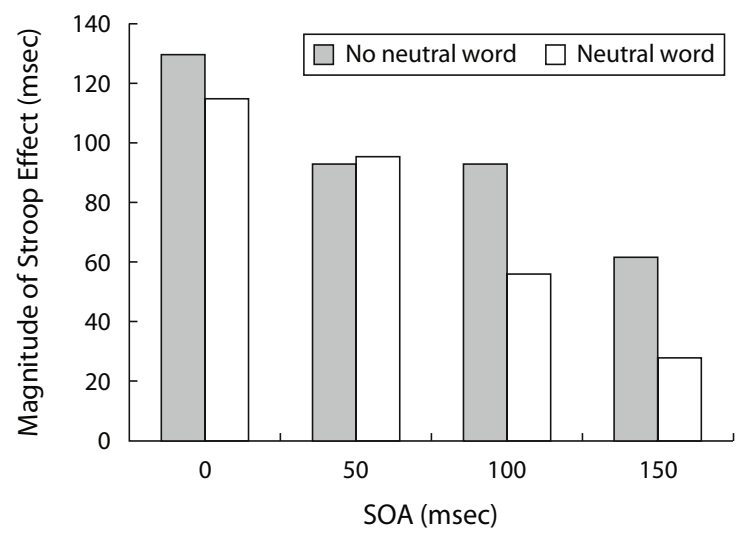

Figure 2. Magnitude of the Stroop effect as a function of stimulus onset asynchrony (SOA) for Experiment 3.

along with the color carrier. The three-way interaction of congruency, SOA, and neutral word was not significant $\left[F(3,45)=1.55, M S_{\mathrm{e}}=890, p=.2139\right]$, even though the Stroop dilution effect was evident only for SOAs of 100 and $150 \mathrm{msec}$. A separate ANOVA of the data from the 0 - and 50-msec SOAs showed that the Stroop dilution effect of $6 \mathrm{msec}$ was not significant $[F(1,15)<1]$, whereas a separate ANOVA for the 100- and 150-msec SOAs showed that the 24-msec Stroop dilution effect was significant $\left[F(1,15)=12.66, M S_{\mathrm{e}}=795, p=.0029\right]$. No other main effect or interaction was significant in the overall ANOVA.

Percentage error. The overall PE was $1.65 \%$. Although the PE tended to decrease as SOA increased $(2.79 \%, 1.83 \%, 1.43 \%$, and $0.52 \%$ for the $0-, 50-, 100$-, and $150-\mathrm{msec}$ SOAs, respectively), the SOA main effect was not significant $\left[F(3,45)=2.54, M S_{\mathrm{e}}=22.35\right.$, $p=.0681]$. A main effect of congruency was obtained, however $\left[F(1,15)=8.02, M S_{\mathrm{e}}=10.40, p=.0126\right]$. The mean PE was $0.20 \%$ when a congruent color word was presented and $3.10 \%$ when an incongruent color word was presented. That is, a $2.90 \%$ Stroop effect was obtained.

The two-way interaction of congruency and SOA approached statistical significance $\left[F(3,45)=2.67, M S_{\mathrm{e}}=\right.$ $26.44, p=.0586]$; the longer the display was presented, the smaller the Stroop effect for PE $(5.59 \%, 3.15 \%$, $2.34 \%$, and $0.52 \%$ for the $0-, 50-, 100-$, and $150-\mathrm{msec}$ SOAs, respectively). No other main effect or interaction was significant.

\section{Discussion}

The meaning of the color word influenced color-naming performance. Namely, we obtained overall Stroop effects of $84 \mathrm{msec}$ and $2.90 \%$. The effect on RTs was modulated by the presence of the neutral word: A 94-msec Stroop effect was found when no neutral word was presented, versus a 74-msec effect when a neutral word was present. That is, a 20-msec Stroop dilution effect occurred. Even though this Stroop dilution effect was smaller than those in Experiments 1 and 2, the most important point is that it was still evident when a color word was presented as the color carrier. As expected, the Stroop effect was modulated by the SOA of the color bar and the color word, decreasing as the SOA increased. This result shows that the postexposed color word still affected the color-naming task, even though its effect was reduced as SOA increased.

Our analysis revealed Stroop dilution effects of $15,-3$, 37 , and $34 \mathrm{msec}$ for the $0-, 50-, 100-$, and $150-\mathrm{msec}$ SOAs, respectively. Although the Stroop dilution effect did not interact significantly with SOA, separate analyses showed that it was statistically reliable at the 100 - and $150-\mathrm{msec}$ SOAs but not at the 0- and 50-msec SOAs. Because the Stroop effect on trials without a neutral word decreased with increasing SOA, whereas the Stroop dilution effect increased, the ratio of the Stroop effect on trials with a neutral word to the effect on those without was much larger at the two shortest SOAs $(0.885$ and 1.032 for the 0 - and $50-\mathrm{msec}$ SOAs) than at the two longest ones $(0.602$ and 0.452 for the 100 - and 150 -msec SOAs).

The results of Experiment 3 provide evidence that the meaning of the color word influences color-naming performance only when attention is oriented to the color word. When a neutral word was available on our trials, attention was likely to shift to it a certain amount of time after the color carrier captured attention. If the color bar was replaced by the color word before an attention shift occurred, the meaning of the color word influenced colornaming performance. If an attention shift occurred before the color bar was replaced, no such influence was obtained. However, when no distractor was available, an attention shift was unlikely to occur, so the color word was always processed to a degree, resulting in a Stroop effect.

\section{GENERAL DISCUSSION}

The purpose of this study was to examine whether the Stroop color-naming effect is best attributed to automatic processing of the color word or to attending to its (taskirrelevant) meaning. We conducted three experiments based on the idea that the magnitude of the Stroop effect is a direct function of the probability that the color word captures visual attention. Both the presentation time of the color word and the presence of an additional neutral word could be thought to modulate the likelihood that attention will shift to the color word when the color carrier and the color word are presented separately. Experiments 1 and 2 showed that, consistent with this idea, the Stroop effect increased with increasing exposure duration of the color word, and the Stroop dilution effect remained a roughly constant proportion of the Stroop effect at all durations, regardless of whether the color word was located at fixation and the color carrier more peripherally, or vice versa. Furthermore, Experiment 3 showed that when a change of the color carrier from a bar to a color word was delayed (thus leaving more time for processing a neutral word), the Stroop effect decreased, but the Stroop dilution effect increased.

Even though some evidence suggests that visual word recognition requires visual attention (see, e.g., McCann, 
Folk, \& Johnston, 1992), many accounts of the Stroop effect are based on the assumption that the color word is automatically recognized, without focused visual attention (e.g., MacLeod \& MacDonald, 2000). If this is so, the color word should be processed whenever it is presented, even when it is outside the focus of visual attention. Also, color word recognition should not be subject to conscious control or interfered with by other processing, even though word recognition processing does not necessarily meet these criteria in an all-or-none way (Brown et al., 2002).

However, word recognition processing in the Stroop task does seem to be subject to a capacity limitation. If word recognition processing required no attention, the Stroop effect should not be modulated by the presence of a neutral word. Several researchers have interpreted the Stroop dilution effect produced in the presence of a neutral word as an indication that word recognition requires attention, and they have attributed the dilution effect to attentional competition between visual stimuli (Cho et al., 2006; Kahneman \& Chajzyk, 1983; Mitterer, La Heij, \&Van der Heijden, 2003). Two results of the present Experiments 1 and 2 implicate attentional processes in color word recognition. First, the Stroop effect increased with display duration, as would be expected if the longer duration allowed more time for attention to shift to the color word. Second, the Stroop dilution effect was a roughly constant proportion of the Stroop effect at each display duration, consistent with the view that attention could be directed to either the color word or the neutral word. Experiment 3 likewise showed that when a change of the color carrier from a bar to a color word was delayed, the Stroop effect decreased while the Stroop dilution effect increased.

Using the traditional Stroop task in which the color and color word are integrated as a single stimulus, MacLeod and Hodder (1998) obtained results that they interpreted as consistent with an attentional account. In their study, after a varying SOA of 50 to $250 \mathrm{msec}$, the color word (but not the to-be-named color) changed (e.g., the word BLUE changed to GREEN, but both appeared in the color red). The Stroop effect for this change condition was no larger than that for a condition in which the color word did not change, a result that MacLeod and Hodder attributed to the first word capturing attention and blocking out recognition of the second word. More recently, MacLeod and Bors (2002) provided evidence that the contribution of the second color word to the Stroop effect is actually greater than that of the first. Although this outcome suggests that attention shifts to the second color word, rather than locking onto the first one, the result is still consistent with the view that attention must be directed to a color word for the word's meaning to affect performance.

In contrast to these attentional accounts of the Stroop dilution effect, Brown et al. (1995) assumed that the color word in a Stroop task display is processed automatically, and they attributed the dilution effect to visual interference between the color word and the neutral distractor at a stage prior to word recognition processing. Their "early visual interference" account suggests that the magnitude of the Stroop effect should be modulated by the visual complexity of the neutral distractor, but evidence has subsequently suggested that it is not. Roberts and Besner (2005) showed that a distracting color word did not appear to be processed when the color carrier presented at the fixation point was a neutral word or a consonant string, whereas the color word was processed when the color carrier was a string of Xs, a string of characters from the top of the keyboard, or a string of digits. That is, the influence of the color word meaning on color naming was modulated by the nature of the color-carrier stimulus but not by its visual complexity. Similarly, Mitterer et al. (2003) used letter strings, pseudowords, and words of similar visual complexity as dilutors and found that the magnitude of the Stroop effect did not differ across these types of dilutors.

Cho et al. (2006) also provided evidence inconsistent with the early visual interference account. They showed that the Stroop dilution effect was evident when the color carrier was a neutral word and a color word was presented as a distractor, but not when the color carrier was a color word and a neutral word was presented as a distractor, regardless of whether the color word was presented at the fixation point or at a peripheral position. Such asymmetry of the interference effects and independence from the words' locations is counter to what would be expected on the basis of early visual interference. If a stimulus presented at fixation were processed in a protected mode, an influence of display duration on the Stroop effect should be evident when the color carrier is presented at fixation and the color word at the periphery, but not when the color carrier is presented at the periphery and the color word at fixation, counter to the results of Experiment 2. The results of the present experiments, along with those of the studies cited in these paragraphs, suggest that the Stroop dilution effect is unlikely to be due to early visual interference between stimuli occurring at a stage prior to word recognition processing.

Cho et al. (2006) found that the Stroop effect decreased as display duration was reduced when the color word was presented as a separate distractor stimulus, but not when the color word was presented as the color carrier. Thus, the meaning of the color word is processed when that word is part of the object that contains the to-be-identified color. If the color word were processed automatically, the size of the Stroop effect would not have varied with display duration, even when the color word was presented as a separate distractor stimulus. More generally, Lamers and Roelofs (2007) provided evidence that factors that reduce gestalt grouping of the color word and the color carrier reduce the size of the Stroop effect, as would be expected if the color word is processed only when it is attended.

Risko, Stolz, and Besner (2005) provided additional evidence that visual word recognition does not occur without visual attention. In their Experiment 1, participants saw displays containing a color word and a variable number of neutral words, with a single word being colored. The task was to classify the color of the colored word by pressing one of four keys. Risko et al. found a 100-msec Stroop 
effect when the color was integrated with the color word, but no effect when the color was integrated with a noncolor word. The number of neutral words in the display did not influence classification performance. When the color carrier was a color bar, in their Experiment 3, no Stroop effect was obtained, either. If the color word were automatically processed to a semantic level whenever it occurred, the Stroop effect should have been evident, regardless of whether the color carrier and the color word were separated or integrated.

On the basis of the results from the aforementioned studies, it is plausible to conclude that, as Kahneman and Chajczyk (1983) suggested, visual attention triggers a recognition process for the color word in the Stroop task. Only when visual attention is directed to the color word does the word's meaning have much influence on colornaming performance. That task performance is influenced by the meaning of a task-irrelevant stimulus does not necessarily indicate that word recognition is an automatic process (see Lachter, Forster, \& Ruthruff, 2004, for a review). Conversely, although attention plays a large role in the Stroop effect and in its dilution by neutral words, a very small part of these effects may be due to processes that do not require attention (Lachter, Ruthruff, Lien, \& McCann, in press).

Although we have favored an attention-shifting account of both the present results and others from the Stroop dilution literature, an alternative possibility is that attention can be divided between color and neutral words. The history of research on attention has shown the difficulty of distinguishing between all-or-none attention-switching models, on the one hand, and limited-resource models in which attention can be allocated to different stimuli or tasks concurrently, on the other (as, for example, in the ongoing debate between all-or-none bottleneck vs. resource accounts of the psychological refractory period effect; see, e.g., Tombu \& Jolicœur, 2005). One finding concerning the Stroop dilution effect that seems more consistent with attention being allocated to a word in an all-or-none manner than with the alternative comes from Cho et al.'s (2006) Experiment 5B. In that experiment, in which a colored color word was presented at fixation, the Stroop effect did not vary as a function of display duration, regardless of whether a neutral word was present. This result implies that, when the color word is presented in such a manner that it captures attention initially, no portion of attention is directed to the neutral word until after the color word is processed fully.

In conclusion, the present results suggest that the Stroop effect is not a consequence of automatic recognition of the color word but of the color word capturing visual attention. Our manipulations of the likelihood that the color word would capture visual attention - including adding a neutral word to the display, varying display duration, and varying the temporal interval between onset of the color and onset of the color word-yielded results consistent with predictions drawn from the attentional-capture account. However, if processing priority is given to the color carrier, as the results of this study imply, it is unclear why participants would shift their visual attention to a separate, task-irrelevant color word after first directing it to the task-relevant color carrier. Our conclusion that they $d o$ shift attention, however, is in agreement with MacLeod and Bors's (2002) evidence that participants continue to monitor the word dimension while they attempt to identify and name the color.

\section{AUTHOR NOTE}

H.K. is currently at the Department of Psychology, University of Colorado at Boulder. This research was supported in part by Grant MOST-2006-05110 from the Korea Science and Engineering Foundation, funded by the Korean government; a Korea University grant; and U.S. Army Research Office Grant W911NF-05-1-0153. We thank Colin M. MacLeod, Jeremy M. Wolfe, and two anonymous reviewers for helpful comments on an earlier version of the manuscript. Correspondence related to this article may be sent to Y. S. Cho, Department of Psychology, Korea University, Anam-Dong Seongbuk-Gu, Seoul, Korea 136701 (e-mail: yscho_psych@korea.ac.kr).

Note-Accepted by the editorial board of Editor-Elect Jeremy M. Wolfe.

\section{REFERENCES}

Brown, T. L., Gore, C. L., \& CARr, T. H. (2002). Visual attention and word recognition in Stroop color naming: Is word recognition "automatic"? Journal of Experimental Psychology: General, 131, 220-240.

Brown, T. L., Roos-Gilbert, L., \& CarR, T. H. (1995). Automaticity and word perception: Evidence from Stroop and Stroop dilution effects. Journal of Experimental Psychology: Learning, Memory, \& Cognition, 21, 1395-1411.

Cho, Y. S., Lien, M.-C., \& Proctor, R. W. (2006). Stroop dilution depends on the nature of the color carrier but not on its location. Journal of Experimental Psychology: Human Perception \& Performance, 32, 826-839.

Cohen, J. D., Dunbar, K., \& McClelland, J. L. (1990). On the control of automatic processes: A parallel distributed processing account of the Stroop effect. Psychological Review, 97, 332-361.

ERIKSEN, B. A., \& ERIKSEN, C. W. (1974). Effects of noise letters upon the identification of a target letter in a nonsearch task. Perception \& Psychophysics, 16, 143-149.

Glaser, M. O., \& Glaser, W. R. (1982). Time course analysis of the Stroop phenomenon. Journal of Experimental Psychology: Human Perception \& Performance, 8, 875-894.

Kahneman, D., \& ChajczyK, D. (1983). Tests of the automaticity of reading: Dilution of Stroop effects by color-irrelevant stimuli. Journal of Experimental Psychology: Human Perception \& Performance, 9, 497-509.

Lachter, J., Forster, K. I., \& Ruthruff, E. (2004). Forty-five years after Broadbent (1958): Still no identification without attention. Psychological Review, 111, 880-913.

LaChter, J., Ruthruff, E., Lien, M.-C., \& McCanN, R. S. (in press). Is attention needed for object identification? Evidence from the Stroop paradigm. Psychonomic Bulletin \& Review.

Lamers, M. J. M., \& Roelofs, A. (2007). Role of Gestalt grouping in selective attention: Evidence from the Stroop task. Perception \& Psychophysics, 69, 1305-1314.

MACLEOD, C. M. (1991). Half a century of research on the Stroop effect: An integrative review. Psychological Bulletin, 109, 163-203.

MacLeod, C. M., \& Bors, D. A. (2002). Presenting two color words on a single Stroop trial: Evidence for joint influence, not capture. Memory \& Cognition, 30, 789-797.

MacLeod, C. M., \& Dunbar, K. (1988). Training and Stroop-like interference: Evidence for a continuum of automaticity. Journal of Experimental Psychology: Learning, Memory, \& Cognition, 14, 126-135.

MacLeod, C. M., \& Hodder, S. L. (1998). Presenting two incongruent color words on a single trial does not alter Stroop interference. Memory \& Cognition, 26, 212-219.

MACLEOD, C. M., \& MaCDonald, P. A. (2000). Interdimensional in- 
terference in the Stroop effect: Uncovering the cognitive and neural anatomy of attention. Trends in Cognitive Sciences, 4, 383-391.

McCann, R. S., Folk, C. L., \& Johnston, J. C. (1992). The role of spatial attention in visual word processing. Journal of Experimental Psychology: Human Perception \& Performance, 18, 1015-1029.

Mitterer, H., La Heis, W., \& Van der Heijden, A. H. C. (2003). Stroop dilution but not word-processing dilution: Evidence for attention capture. Psychological Research, 67, 30-42.

Moors, A., \& De Houwer, J. (2006). Automaticity: A theoretical and conceptual analysis. Psychological Bulletin, 132, 297-326.

Posner, M. I., \& SNyder, C. R. R. (1975). Attention and cognitive control. In R. L. Solso (Ed.), Information processing and cognition: The Loyola symposium (pp. 55-85). Hillsdale, NJ: Erlbaum.

Risko, E. F., Stolz, J. A., \& Besner, D. (2005). Basic processes in reading: Is visual word recognition obligatory? Psychonomic Bulletin \& Review, 12, 119-124.

Roberts, M. A., \& Besner, D. (2005). Stroop dilution revisited: Evidence for domain-specific, limited-capacity processing. Journal of Experimental Psychology: Human Perception \& Performance, 31, 3-13.

RoELofs, A. (2003). Goal-referenced selection of verbal action: Modeling attentional control in the Stroop task. Psychological Review, 110, 88-125.
SCHNEIDER, W., \& SHIFfrin, R. M. (1977). Controlled and automatic human information processing: I. Detection, search, and attention. Psychological Review, 84, 1-66.

SHIFFrin, R. M., \& SchneIDER, W. (1977). Controlled and automatic human information processing: II. Perceptual learning, automatic attending and a general theory. Psychological Review, 84, 127-190.

Simon, J. R. (1990). The effects of an irrelevant directional cue on human information processing. In R. W. Proctor \& T. G. Reeve (Eds.), Stimulus-response compatibility: An integrated perspective (pp. 3186). Amsterdam: North-Holland.

STRoop, J. R. (1935). Studies of interference in serial verbal reactions. Journal of Experimental Psychology, 18, 643-662.

Tombu, M., \& Joliceur, P. (2005). Testing the predictions of the central capacity sharing model. Journal of Experimental Psychology: Human Perception \& Performance, 31, 790-802.

YeE, P. L., \& HunT, E. (1991). Individual differences in Stroop dilution: Tests of the attention-capture hypothesis. Journal of Experimental Psychology: Human Perception \& Performance, 17, 715-725.

(Manuscript received March 16, 2008; revision accepted for publication June 14, 2008.) 